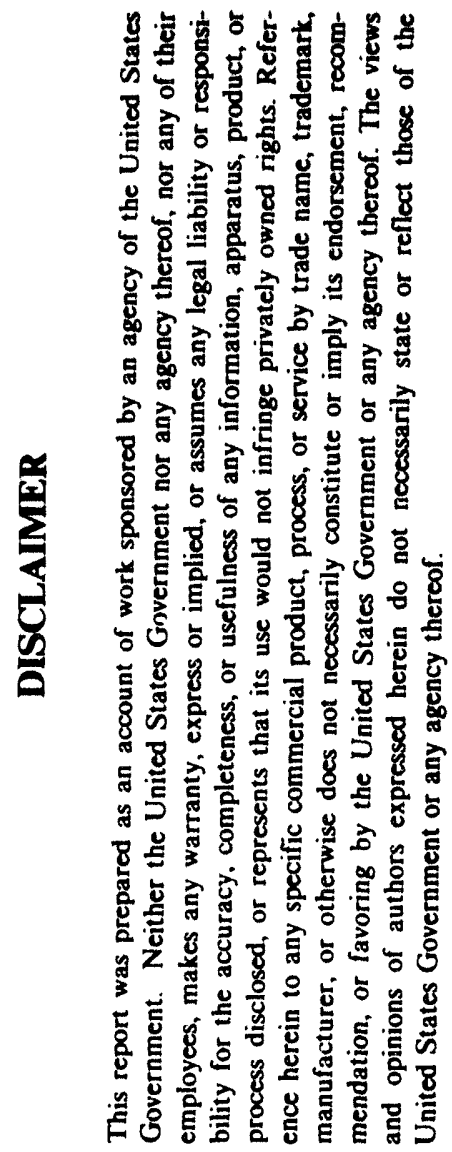

\title{
$\min$ \\ THE EXPERIMENTAL PHYSICS AND INDUSTRIAL CONTROL SYSTEM ARCHITECTURE: PAST, PRESENT AND FUTURE
}

L. R. Dalesio, J. O. Hill, M. Kraimer, S. Lewis,

D. R. Murray, S. M. Hunt, M. Claussen, W. Watson,

J. Dalesio

\section{Submitrod in:}

ICALEPCS '93 Conference

Berlin, Germany

October 18-22, 1993

\section{Los Alamos} nATIONAL LABORATOAY

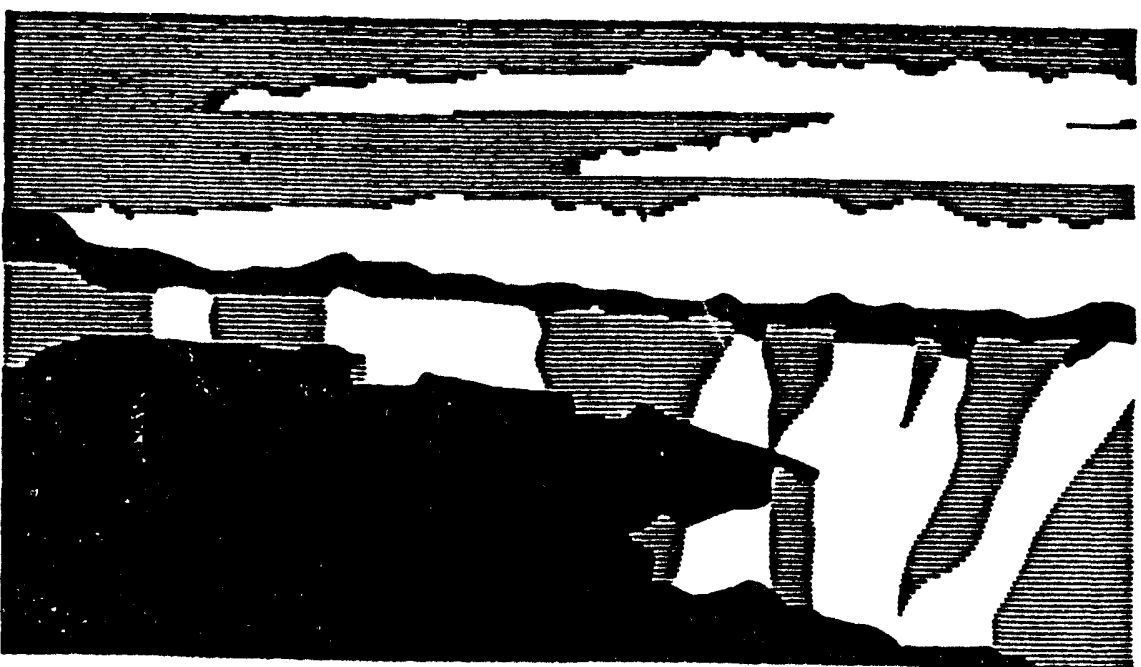

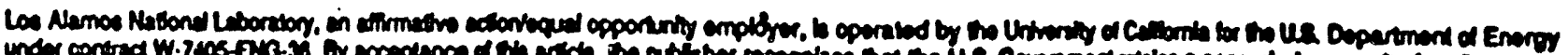

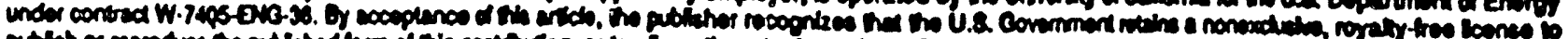

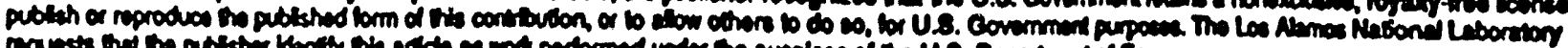

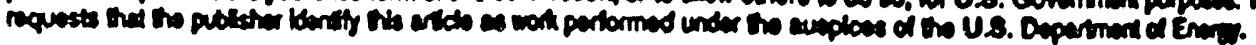


THE EXPERIMENTAL PHYSICS AND INDUSTRIAL CONTROL SYSTEM ARCHITECTURE:

PAST, PRESENT, AND FUTURE*

Leo R. Dalesio, Jeffrey O. Hill, Los Alamos National Laboratory (LANL)

Martin Kraimer, Argonne National Laboratory (ANL)

Steven Lewis. Lawrence Berkeley Laboratory (LBL)

Douglas Murray, Stephan Hunt. Superconducting Super Collider Laboratory (SSCL)

Matthias Claussen, Deutches Elektronen-Synchrontron (DESY)

William Watson, Continuous Electron Beam Accelerator Facility (CEBAF)

John Dalesio, Tate Integrated Systems (TIS)

\section{Abstract:}

The Experimental Physics and Industrial Control System (EPICS), has been used at a number of sites for performing data acquisition, supervisory control, closed-loop control, sequential control, and operational optimization. The EPICS architecture was originally developed by a group with diverse backgrounds in physics and industrial control. The current architecture represents one instance of the 'standard model'. It provides distributed processing and communication from any LAN device to the front end controllers. This paper will present the genealogy. current architecture, performance envelope. current installations, and planned extensions for requirements not met by the current architecture.

- Work supported under the U.S. Department of Energy, Office of Basic Energy Sciences under Contract Nos. (W-7405-ENG-36), (W-31-109-ENG-38) and (DE-AC02-89ER40486) 


\section{Introduction:}

The Experimental Physics and Industrial Control System (EPICS), has been used at a number of sites for performing data acquisition, supervisory control, closed-loop control, sequential control, and operational optimization. The current EPICS collaboration[1] consists of five U.S. laboratories; Los Alamos National Laboratory. Argonne National Laboratory, Lawrence Berkeley Laboratory, the Superconducting Super Collider Laboratory, and the Continuous Electron Beam Accelerator Facility|2]|3]|4 ||5]|6]. In addition, there :re three industrial partners and a number of other scientific labs and universities using EPICS. This paper will present the genealogy, current architecture, performance envelope, current installations, and planned extensions for requirements not met by the current architecture.

\section{Design History:}

EPICS was developed by a group with experience in control of various complex physics processes and industrial control. Three programs preceding the EPICS development were high order beam optics control, single shot laser physics research, and isotopic refinery process control. These systems were all developed between 1984 and 1987. These three programs embodied different aspects of data acquisition, control and automation. They used equipment and methods most appropriate for the time and scope of their respective problems. The Ground Test Accelerator project, where EP. ICS development began as GTACS|7|, required fully automated remote control in a flexible and extensible environment. These requirements encompassed aspects from all of the previous control system experience. The design group combined the best features of their past, like distributed control. real-time front-end computers, interactive configuration tools, and workstation based operator consoles. while taking advantage of the latest technology, like VME, VXI, X-windows, MOTIF, and the latest processors (table 1). The major enabling innovation was the channel access communication protocol. Since the collaboration began. major steps have been made in portability between sites, extensibility in database and driver support, and there is added functionality like the alarm manager, know manager and interfaces to Mathmatica and PV-Wave. The EPICS name was adopted after the present multi-lab collaboration began.

\begin{tabular}{|c|c|c|c|c|}
\hline & $\begin{array}{l}\text { One shot laser } \\
\text { physics }\end{array}$ & $\begin{array}{l}\text { High Order Beam } \\
\text { Optics }\end{array}$ & $\begin{array}{l}\text { Isotopic Refinery } \\
\text { Process Control }\end{array}$ & GTACS/EPICS \\
\hline Architecture & Hierarchical & Single Computer & Distributed & Distributed \\
\hline Signal Count & $-4,000)$ & $-3(x)$ & -4.000 & $-30,000)$ \\
\hline Field Bus & STD/CAMAC & CAMAC & Industrial & $\begin{array}{l}\text { VME/VXI/ } \\
\text { GPIB/Industrial } \\
\text { Bitbus/CAMAC }\end{array}$ \\
\hline Front end & VAX & VAX & 6800 & $680 \times 0$ \\
\hline $\begin{array}{l}\text { Operator } \\
\text { Interface }\end{array}$ & VAX & VAX & $6800 \mathrm{w} /$ lexidata & $\begin{array}{l}\text { SUN/HP/ } \\
\text { Decstation }\end{array}$ \\
\hline Network & DecNet/RS232 & DecNet & MAP & TCP/IP \\
\hline Special I/O & $\begin{array}{l}\text { 20) TDRs } \\
\text { Positioning }\end{array}$ & $\begin{array}{l}\text { Video) Diagnostic } \\
\text { Positioning }\end{array}$ & $\begin{array}{l}\text { High Rep Rate } \\
\text { Closed-locop con- } \\
\text { trol }\end{array}$ & Full Complement \\
\hline $\begin{array}{l}\text { Oflline } \\
\text { Configuration } \\
\text { To(x)ls }\end{array}$ & none & displilys & $\begin{array}{l}\text { displays, alarms, } \\
\text { I/O, control, and } \\
\text { archive requests }\end{array}$ & $\begin{array}{l}\text { displays, alarms, } \\
\text { I/O. control, and } \\
\text { archive requests }\end{array}$ \\
\hline
\end{tabular}

Table 1. Architectural History 


\section{Current Architecture:}

The EPICS architecture[8] represents an instance of the 'standard model'.[9] There are distributed workstations for operator interfaces, archiving and global data analysis. There is a local area network for communicating peer-to-peer and a set $c^{f}$ ingle board computers for supporting $1 / O$ interfaces, closed-loop control, and sequential control.

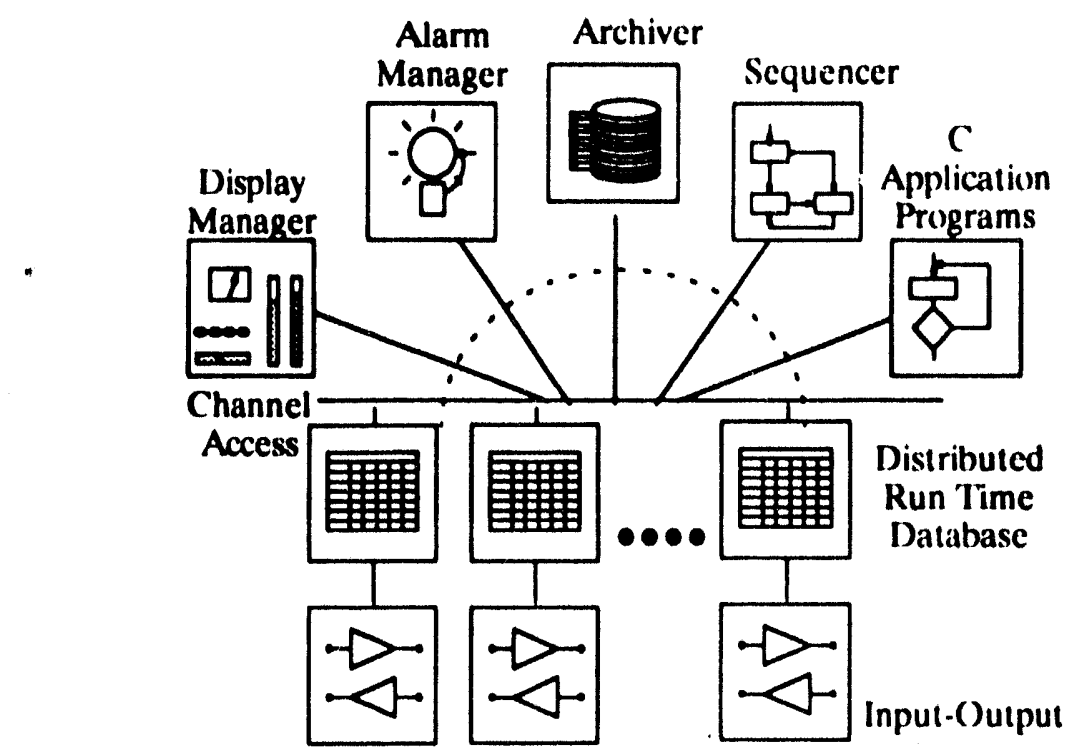

Figure 2. Software Architecture

The software design incorporates a coilection of extensible tools interconnected through the channel access communication protocol $[10] \mid 11]|12||13||14| \mid 15] \mid[16]$ (figure 2 ). The software architecture allows the users to apply EPICS on the single board computers (SBC) to implement control and data acquisition strategies, to create state notation programs, and to implement sequential control. (figure 3). All data is passed through the channel access protocol using gets, puts, or monitors (notification on change). One can extend the basic EPICS system in the SBC by creating new database record types. calling ' $C$ ' subroutines from the database, extending the driver support, and creating independent vxWorks tasks. Workstation based tools are frequently developed to accommodate unique operator requirements, to integrate physics codes or to take advantage of some commercial package. Some examples are video diagnostics. WingZ. PV-Wave. Mathmatica, and a serial knob manager. The EP. ICS software architecture provides a flexible environment for resolving problems that extend beyond its own limitations.

\section{Performance:}

The $1 / O$ Controller provides a physical interface to a portion of the machine. The limiting factors in the performance of the IOC are the CPU bandwidth and memory. Table 2 shows the measured performance of analog, binary inputs, and monitors. Analog inputs read a value, convert it to engineering units, and compare the alarm limits. If channel access notification is required, an additional 1(X) us is incurred. It is important to note that most signals are not monitored by channel access clients and that monitors are only sent on change of state or excursion outside of a dead-band. In the average case. a signal being processed will not post monitors. Periodic scan rates vary from $6(1) \mathrm{Hz}(1)$ once every 10 minutes. In addition, records can be processed on end-of-conversion and change-of-state. For binary inputs, change-of-state support in the device driver significantly reduces the CPU utilization as discrete values rarely change. For analog inputs, scanning on end-of-conversion signilicantly reduces the latency between gating a signal and processing the record. This may be uscful for pulse to pulse closed lixop control. The scheduling and dead-bands should be selected to best fit the situation. For instance, a transducer that may change within $50 \mathrm{msec}$ but is accurate 102 units should be pro- 


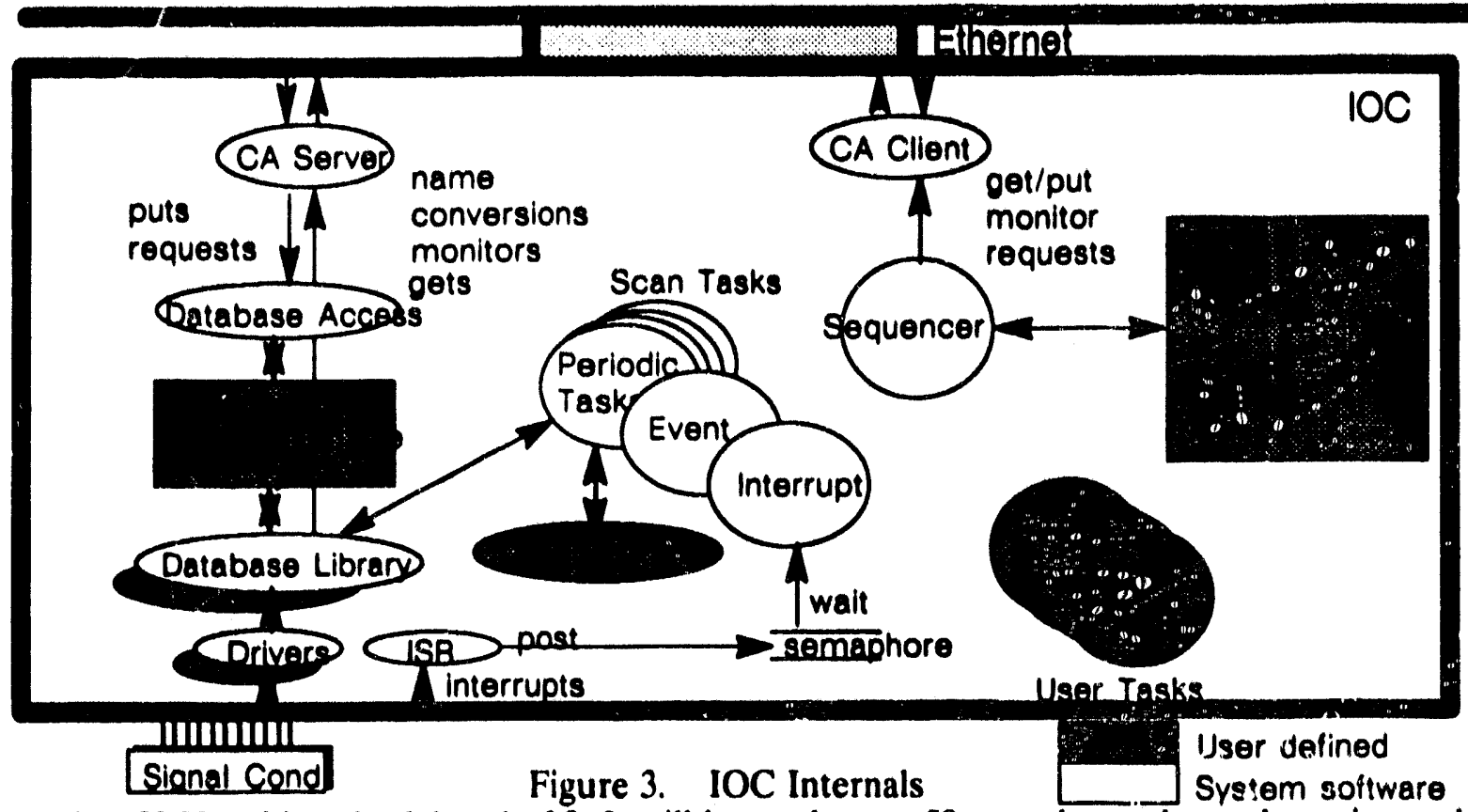

cessed at $20 \mathrm{~Hz}$ with a dead-band of 2 . It will be read every $50 \mathrm{msec}$ but only send monitors when the value changes by more than the jitter. The database scanning is flexible to provide optimum performance and minimum overhead.

\begin{tabular}{|l|c|c|c|c|}
\hline & $\begin{array}{c}\text { number of bytes } \\
\text { per instance }\end{array}$ & $\begin{array}{c}\text { instances to use } \\
1.5 \mathrm{M} \text { Byles }\end{array}$ & $\begin{array}{c}\text { useconds each } \\
68040 \text { (MV167) }\end{array}$ & $\begin{array}{c}\text { CPU Usage (a } \\
1,000 / \text { second }\end{array}$ \\
\hline A/D Conversions & 576 & 2,600 & 61 usec each & $06.1 \%$ \\
\hline Binary Inputs & 480 & 3.100 & 52 usec each & $05.2 \%$ \\
\hline Monitors & $32.000 /$ client & 46 clients & 100 usec each & $10.0 \%$ \\
\hline
\end{tabular}

Table 2. I/O Controller Measured Resource [17]

Communication performance is limited by the channel access protocol, TCP/IP packet overhead, and the physical communication media. Channel access optimizes its use of the TCP/IP packet overhead, by attempting to pack each message up to around $1 \mathrm{KBytes}$. For a point to point connection. 1.000 monitors per second will use about $3 \%$ of the $10 \mathrm{Mbit}$ ethernet band-width. To avoid collisions and therefore avoid non-determinism, the ethernet load is kept at 15\%. At this level, we can issue 5.(X)() monitors per second. Performance can be doubled by optimizing the channel access proticol from a fixed to variable command format and by compressing timestamps on monitors. However, most of the potential performance gain comes from using commercially available hardware. By applying bridges or an etherswitch, the bandwidth can easily be tripled. Going to a $1(X)$ Mbit ethernet yields a 10 times performance improvement. Using 100 Mbit FDDI provides a 10 times faster media but also has 4 times more available bandwidth $(60) \%$ utilization), since it is a token based scheme. The Ground Test Accelerator, with 2,50) physical connections and 10,000) database records distributed among 14 IOCs and controlled by 8 workstations. used only between $5-7 \%$ of our 10 Mbit ethernet during operation. Standard communication hardware provides performance improvements to about 400,000 notifications per second which should comfortably support systems of up to $60.0(0)$ () physical connections.

\section{Installations:}

EPICS is in use at a number of scientific laboratories, universities and commercial installations. Table 3 presents a summary of some of these installations, the number of signals. IOCs, and workstations installed and the projected number of signals on completion. The EPICS soltware is typi- 
cally used in systems between 200 and 30,000 signals. The SSC is a unique case at $1,000,000$ signals projected. Although we have run a number of tests to characterize the operating parameters for EP. ICS, the largest installation that has been operated has only 2.500 physical connections and 10,000 database records. The CEBAF. APS, and GTA isntallations will be growing at a very rapid rate over the next 12 monihs where each will bringing thousands of new connections on-line. The real test of the extensibility of EPICS will come as these installations reach full operation.

\begin{tabular}{|l|l|l|l|l|}
\hline & $\begin{array}{l}\text { Signals im- } \\
\text { plemneted }\end{array}$ & $\begin{array}{l}\text { Single Board } \\
\text { Computers } \\
\text { Installed }\end{array}$ & $\begin{array}{l}\text { Workstations } \\
\text { Installed }\end{array}$ & $\begin{array}{l}\text { Signals on } \\
\text { completion }\end{array}$ \\
\hline Ground Test Accelerator & 2,500 & 14 & 8 & 10,000 \\
\hline Advanced Photon Source & $-1,200$ & 8 & 6 & 30,000 \\
\hline Gammasphere & 150 & 8 & 6 & 3,000 \\
\hline $\begin{array}{l}\text { Superconducting Super } \\
\text { Collider }\end{array}$ & 200 & 3 & 1 & $1,000,000$ \\
\hline CEBAF & 0 & 0 & 0 & 50,000 \\
\hline Duke Mark III IR FEL & 380 & 1 & 2 & 380 \\
\hline
\end{tabular}

Table 3. Installations of EPICS

\section{Extensions:}

There are a number of extensions required to meet the needs of the laboratories currently specifying EPICS. The major shortcomings in the EPICS environment revolve around configuration tools, communication support issues, and some general system functions. The manpower required to do the effort is distributed among the collaborating labs and is certainly adequate to make these additions.

We have several significant development and tool integration efforts going on at several sites to bring the configuration tools up to modern standards. Most of these efforts are directed at graphical configuration tools. Another critical aspect of these configuration tools is the maintenance of very large configuration files over the lifetime of the programs. The most promising combination secms to be a graphical configuration tool that interfaces to a relational database. This combines easy visualization during configuration of a specilic portion of the application with the ability to use the querying capabilities for locating things after the fact.

\begin{tabular}{|l|l|l|}
\hline $\begin{array}{l}\text { Needed extension for configuration } \\
\text { tools }\end{array}$ & Solution & Work in progress \\
\hline Graphical database configuration & $\begin{array}{l}\text { Use Objectviews as basis for t(x)l } \\
\text { Use schematic capture program }\end{array}$ & $\begin{array}{l}\text { ANL. SSCL } \\
\text { LANL. CEBAF }\end{array}$ \\
\hline Graphical state notation language & Use Objectviews as basis for t(x)l & SSCL \\
\hline $\begin{array}{l}\text { Extend Graphical Display Conligura- } \\
\text { tion }\end{array}$ & $\begin{array}{l}\text { Motif based } \\
\text { X-based }\end{array}$ & $\begin{array}{l}\text { ANL } \\
\text { LANL }\end{array}$ \\
\hline Graphical Alarm Configuration & Motif-based & ANL \\
\hline System Configuration & Use a relational database - D-BASE & $\begin{array}{l}\text { Tate } \\
\text { CEBAF }\end{array}$ \\
\hline Graphical Archive Configuration & $\begin{array}{l}\text { Use Alarm Configuration l(x)l as ba- } \\
\text { sis }\end{array}$ & Nonc \\
\hline
\end{tabular}


Table 4. Configuration Extensions

The communication support issues are just being addressed, as the channel access protocol is the basis for all compatibility. We have run the same version of the channel access protocol for the past three years. The requirements forcing us to finally revisit channel access are support for serial communication media, incorporation of different data stores, and the need to support user facilities. We are maintaining compatibility at the subroutine interface level so that all of the current channel access clients and servers will only require recompilation and relinking. These requirements are driving the current channel access upgrade.

\begin{tabular}{|l|l|l|}
\hline Problem & Solution & Work in progress \\
\hline $\begin{array}{l}\text { Need dedicated point to point com- } \\
\text { munication }\end{array}$ & $\begin{array}{l}\text { Add an option to use a name server } \\
\text { Add drivers for serial and T1 }\end{array}$ & $\begin{array}{l}\text { Tate, } \\
\text { LANL }\end{array}$ \\
\hline Access protection & $\begin{array}{l}\text { Add access control based on user, lo- } \\
\text { cation, channel, and machine mode }\end{array}$ & ANL. LANL \\
\hline $\begin{array}{l}\text { Need closed-loop control across the } \\
\text { network }\end{array}$ & $\begin{array}{l}\text { Add multi-priority channel access } \\
\text { connections }\end{array}$ & LANL \\
\hline Connect to alternate data stores & $\begin{array}{l}\text { Port the channel access server to dif- } \\
\text { ferent data stores }\end{array}$ & DESY. LANL \\
\hline $\begin{array}{l}\text { Support a multitude of operator inter- } \\
\text { faces }\end{array}$ & $\begin{array}{l}\text { Create a data gateway to clients that } \\
\text { are able to withstand a single point of } \\
\text { failure and the added latency }\end{array}$ & LANL \\
\hline IOC memory limitations & Size server queues according to need & LANL \\
\hline $\begin{array}{l}\text { Socket and task limitations in the } \\
\text { IOC }\end{array}$ & $\begin{array}{l}\text { Take advantage of the newly working } \\
\text { vxWorks Select }\end{array}$ & Tate. LANL \\
\hline Long time-outs on disconnect & $\begin{array}{l}\text { Add a time-out heartbeat when } \\
\text { theres no traffic on a connection }\end{array}$ & Tate. LANL \\
\hline
\end{tabular}

Table 4. Channel access extensions

Other system wide functions are needed by several of the facilities. The ability to add and de. lete signals during operation, redundant IOCs for critical processes, and a general save and restore of operating parameters are necessary functions for many of these facilitics.

We are currently exploring options for providing the much needed support for planning extensions, reintegration of new functionality, testing new releases, doucmenting new releatses and functionality, distributing new releases, and offering support for installation, application, and upgrades of EPICS installations. In the past, we supported the EPICS installations through direct program funding. As the collaboration has grown, this has proven to be more difficult. We have recently identified this integration need as requiring dedicated manpower and equipment with an explicit charter to provide this support.

There are signilicant pieces of development required to make EPICS a complete solution for experimental physics. Most of the tasks are currently under development at the collathorating labs or the industrial partners. We are exploring options for providing good user support for the F.PICS community. The functional specilications and design for these added lasks have been reviewed by the collaboration members and have been approved. The collaboration works as a single group (o) specify and design additions 10 EPICS, drawing from the strength and numbers available through al collaboration. 


\section{Conclusion:}

The EPICS toolkit provides an environment for implementing systems that range from small test stands requiring several hundred points per second to large distributed systems with tens of thousands of physical connections. The application of EPICS requires a minimum amount of programming. The EPICS environment supports system extensions at all levels, enabling the user to integrate other systems or extend the system for their needs. Work is underway to provide a more integrated application development environment. The base software is also being extended to support some of the fundamental needs of the projects that are controlling user facilities. Through the modular software design which supports extensions at all levels, we are able to provide an upgrade path to the future as well as an interface to an installed base. With the addition of a support group, we will be able to provide a stable starting point complete with an upgrade path, for those programs choosing to use the EPICS toolkit.

\section{Acknowledgement}

There are now several chapters in the EPICS story with close to one hundred folks contributing thus far. The decision to collaborate with member labs has responsilibities to support your fellow collaborators as you would your own programs. This responsibility has received the necessary managerial support from each of the five member laboratories to provide the environment for a successful collaboration. The ability to develop system software in a collaborative environment requires a real dedication to finding the best solution. The system designers that have been involved in this collaboration have been egoless in their search for the best answer resulting in concensus design. Finally, there are the application engineers who have continually provided suggestions for upgrades and extensions. Their dedication to using these tools make it possible to create a toolkit. The application engineers at every site have supported our efforts even through some challenging times. All of the teams at Los Alamos National Laboratory, Argonne National Laboratory, Lawrence Berkeley Laboratory, the Superconducting Super Collider Laboratory, and the Continuous Electron Beam Accelerator Facility are responsible for the success in codeveloping software. It is certainly rewarding to work with such a wide range of experience and knowledge.

\section{References}

II Knoll, M.. Thuot, M., (Gurd, D., Lewis. S., "EPICS: A Control System Software Co-Development Success Story. " submitted to International (onnlerence on Accelerator and Large Experimental Physics Control Systems, Beriin, Germany ()ctuber 18-22.1993.

12) Gurd, D., "Control System Plans and Progress at the SSC," submitted to International Conference on Accelerator and Large Experimental Physics Control Systems, Berlin, (iermany ()etuber 18-22, 1993.

13) Knotl. M.J., M.lDowell, W.P., Lenkšus, F.R., Kraimer, M.R., Arnold, N.R., Daly, R.I., Gunderson, (3.K., ('ha, B.K., and Anderson, M.1)., "The Advanced Photon Source ('ontrol System," in Proceedings of the 1991 IEEE Purticle Accelerutor Confirence. (Sin Franciscor), California, 1991), pp. 2526-2528.

14] Clausen, M.. "(ontrol for the TESLA Test Facility - Status and Future Plans," submitted to International Conference on Accelerator and Large Experimental Physics Control Systems, Berlin, Germany ()etober $18-22.1993$.

15] Watson III. W. A., Barker, D., Bickley. M., (jupta, P., Johnsoon, R. P.. "The (EBAAF Accelerator Control System: Migrating Frum A TAC 'L To An EPICS Based System" submitted to International Conference on Accelerator and Large Experimental Physics ('ontrol Systems, Berlin, (jermany ()etober 18-22. 1993.

|6| Young. J. A.. Cl. al."Status al the Advinced Light Source Control System," submitted to Internationall Conference on Accelerator and Large Experimental Physics Control Systems, Berlin. (iermany ()etober 18-22. 1993. 
(7) Kozubal, A. J., Kerstiens, D. M., Hill, J. (., Dalesio, L. R., "Run-time Environment and Application Tixols for the Ground Test Accelcrator Control System," in Proceedings of International Conference on Accelerutor and Large Experimental Physics Control Systems, D. P. Gurd and M. Crowley-Milling, Eds. (ICALEPCS, Vancouver, British Columbia, Canada. 1989), pp. 288-291.

[8] Dalesio, L. R., Kraimer, M.R., Kozubal, A. J., "EPICS Architecture," in Proceedings of Internutional Conference on Accelerator and Large Experimental Physics Control Systems, C. O. Pac. S. Kurokowa and T: Katoh, Eds. (ICALEPCS, KEK, 'Isukuba, Japan, 1991), pp. 278-282.

[9] Kuiper, B., "Issues in Accelerator Controls," in Proceedings of International Conference on Accelerutor und Large Experimental Physics Control Systems, C. O. Pac, S. Kurokowa and T. Katoh, Eds. (ICALEPCS, KEK. Tsukuba, Japan, 1991), pp. 602-611.

[10] Dalesio, L. R., "The Ground Test Accelerator Database: A Generic Instrumentation Interface," in Proceedings of International Conference on Accelerator and Lange Experimental Physics Control Systems, D. P. Gurd and M. Crowley-Milling, Eds. (ICALEPCS, Vancouver, British Columbia, Canada, 1989), pp. 405-407.

[11) Dalesio, L. R., "The GTA Control System Database: Configuration, Runtime Operation and Access," in Proceedings of the 1989 IEEE Particle Acelerutor Conference. (PAC, Chicago, II., USA. 1989), pp. 1693-1694.

[12] Hill, J., Kerstiens, D., and Dalesio, L.R.. "A Virtual Control Panel Configuration Tix)l for X-Window System," in Proceedings of Internutional Conference on Accelerator and Large Experimental Physics Control Systems, C. O. Pac, S. Kurokowa and 'T. Katoh. Eds. (ICALEPCS, KEK, Tsukuba, Japan, 1991), pp. 468-470).

[13] Kraimer, M.R., Cha, B.C., and Anderson, M.D., "Alarm Handler for the Advanced Photon Source Control System," in Proceedings of the 1991 IEEE Purticle Accelerator Conference, (San Francisco, (alifornia, 1991), pp. 1314-1316.

[14] Hill, J. O., "Channel Access: A Software Bus for the LAACS," in Proceedings of International Conference on Accelerator and Lange Experimental Physics Control Systems, D. P. Gurd and M. Crowley-Milling. Eds. (ICALEPCS, Vancouver, British Columbia, Canada, 1989), pp. 288-291.

[15] Kozubal, A. J., L. R. Dulesio, J. (). Hill, and D. M. Kerstiens, "A State Notation Language for Autumatic Control," Los Alamos National Laboratory report LA-UR-89-3564, November, 1989.

[16] Cole, R., Atkins, W., "Real-Time Data Archiving for (jTA," Los Alamos National Laboratory report LA-UR-92-2420, AUgust, 1992.

|17] Botlo, M., Romero, A., "EPICS Performance Evaluation". SSCL-644, 1993. 


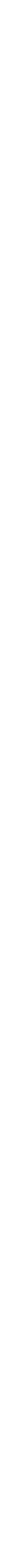




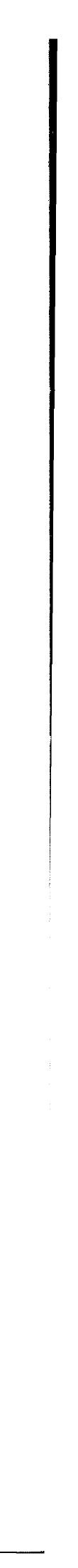

